\title{
Biomaterials Applied to the Bone Healing Process
}

\author{
Biomateriales con Aplicación en el Proceso de Reparación Ósea \\ Cássio do Nascimento; João Paulo Mardegan Issa; Rafael Ramos de Oliveira; \\ Mamie Mizusaki Iyomasa; Selma Siéssere \& Simone Cecílio Hallak Regalo
}

NASCIMENTO, C.; ISSA, J. P. M.; OLIVEIRA, R. R.; IYOMASA, M. M.; SIÉSSERE, S. \& REGALO, S. C. H. Biomaterials applied to the bone healing process. Int. J.Morphol., 25(4):839-846, 2007.

SUMMARY: An recent innovation in medicine is the application of the biomaterials in bone healing process. Thus, this work has the objective to present an overview of the uses and insertions of these biomaterials and its components mostly used in the bone repair.

KEY WORDS: Bone repair; Biomaterials; Cicatricial process.

\section{INTRODUCTION}

Biomaterials are used in medical devices, particularly in those applications for which the device either contacts or is temporarily inserted or permanently implanted in the body. The material selection requirements are determined by the specific device application. For blood-contacting applications, these materials are components of extracorporeal devices that remove and return blood from the body, devices that are inserted into a blood vessel, or devices that are permanently implanted. For soft tissue device applications, the materials are typically implanted into soft tissue to augment or redefine the tissue. In orthopedic and dental applications, the materials are components of structural implants or are used to repair bony defects.

In practical sense, biomaterials are synthetic polymers, metals, ceramics, and natural macromolecules, i.e. biopolymers, which are manufactured or processed to be suitable for use in or as a medical device that comes into intimate contact with proteins, cells, tissues, organs, and organ systems. Recently, a variety of polymers, biopolymers, and inorganics have been developed specifically for medical applications. Composite materials are finding applications in orthopedic and dental implants. Bioactive ceramic coatings for orthopedic and dental implant applications have been used to encourage bony attachment.

In this way, the aim of this article is to supply an overview of the mostly biomaterials used on the bone healing process.
Overview of biomaterials related to bone repair.

1. Bone grafts. Autogenous bone is derived from the individual for whom the graft is intended. It has long been considered the gold standard of the biomaterials used applied to the bone repair. It consists of two components. The first is a natural anatomical structure for scaffolding cellular invasion and for graft and host site support. The second offers a component of primarily type I collagen that provides pathways for vascularity and resilience. The vitality of such grafts may vary in their duration, some lasting a shorter duration than desired. Such grafts are harvested from the surgical patient from whom a second surgical wound site must be used. The use of autogenous bone, however, offers the promise of high levels of success while avoiding the possibilities of antigenicity (Reynolds \& Bowers, 1996; Smukler et al., 1999) (Fig. 1).

Allografts are tissues taken from individuals of the same species as the hosts. There are three main divisions: (1) frozen, (2) freeze-dried, and (3) freeze-dried demineralized. They come in different forms: particulate, gels, and putties. A major advantage of their use is that the material is readily available, without the requirement of a secondary surgical site. They provide a source of type I collagen, which is the sole organic component of bone. However, they do not produce the inorganic calcium or scaffolding necessary for bone regeneration. Allographic bone must be processed to guarantee safety (Becker et al., 1994; and Piatelli et al., 1996) (Fig. 2). 


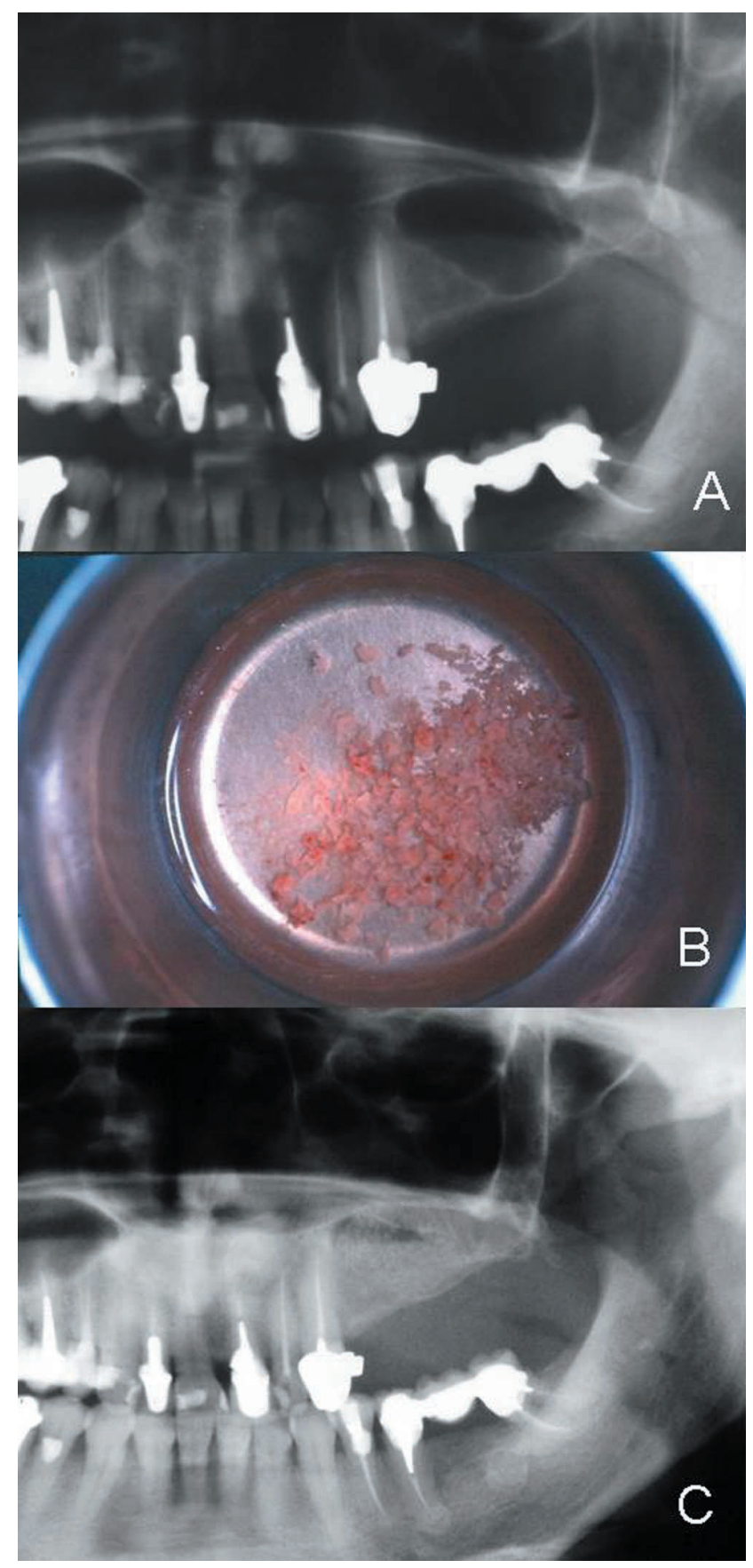

Fig. 1. Autogenous bone. (A) X-ray showing a pneumatized maxillary sinus; (B) autogenous bone chips removed from the chin; (C) X-ray after sinus lift procedure showing the filling of the cavity.

Alloplasts are synthetic. They contribute to the repair of osseous defects and to the enhancement of osseous ingrowth. The chemical composition, physical form, and differences in surface configuration result in varying levels of bioresorbability. The varying nature of available commercial graft materials (porosity, geometries, differing solubilities and densities) will determine the resorption of

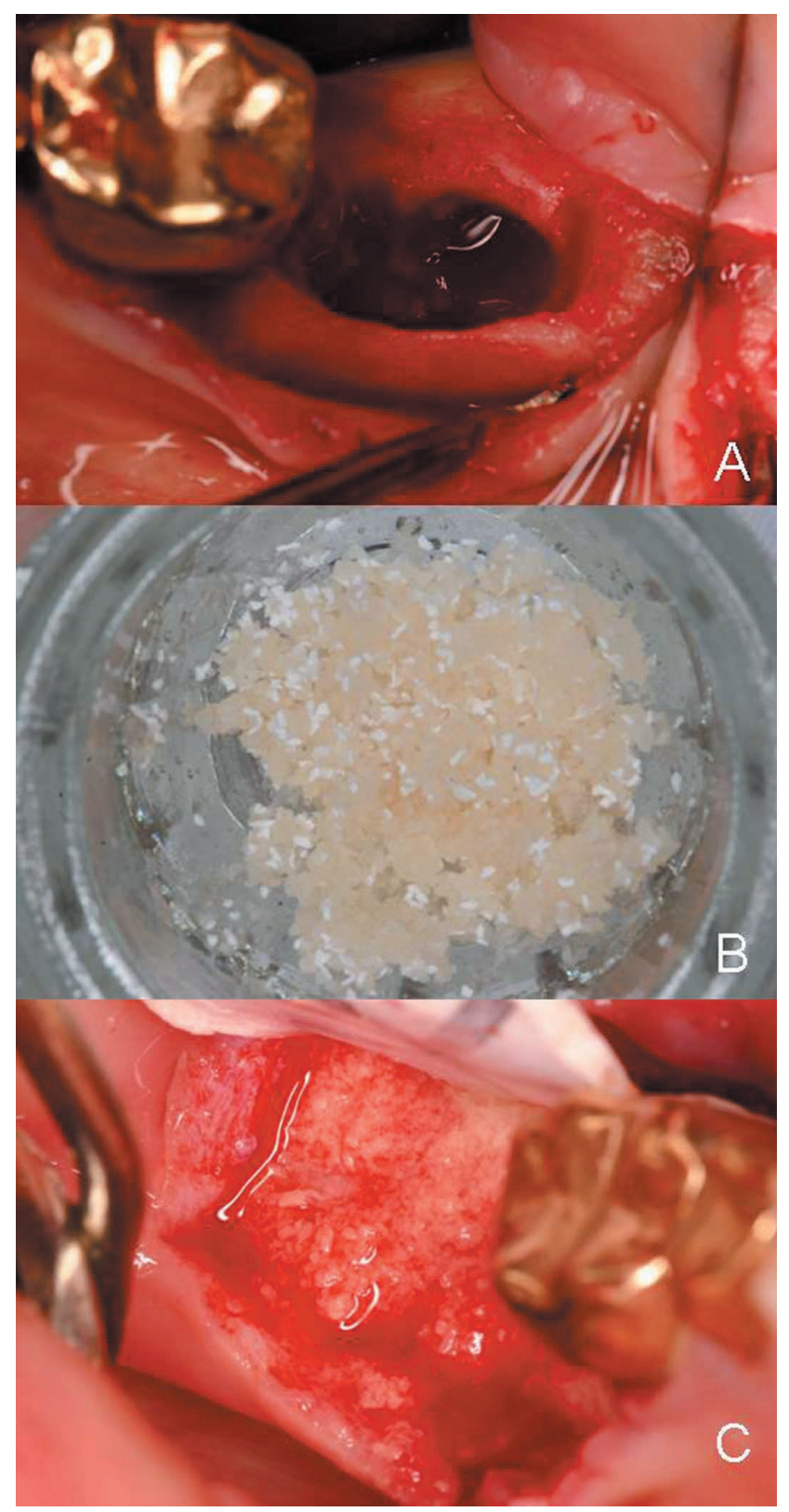

Fig. 2. Allograft material. (A) clinical aspect of a mandibular bone defect; (B) freeze-dried demineralized bone allograft; (C) biomaterial filling the bone defect associated with a non-absorbable barrier.

these calcium phosphate-based graft materials (Yukna, 1994; Evans et al., 1997).

Xenografts are derived from other species. They are materials with their organic components totally removed. With their removal, concern about immunological reactions becomes nonexistent. The remaining inorganic structure provides a natural architectural matrix as well as an excellent source of calcium (Zaner \& Yukna 1984; Callan \& Rohrer 1993; Yukna et al., 1998). The inorganic material also 


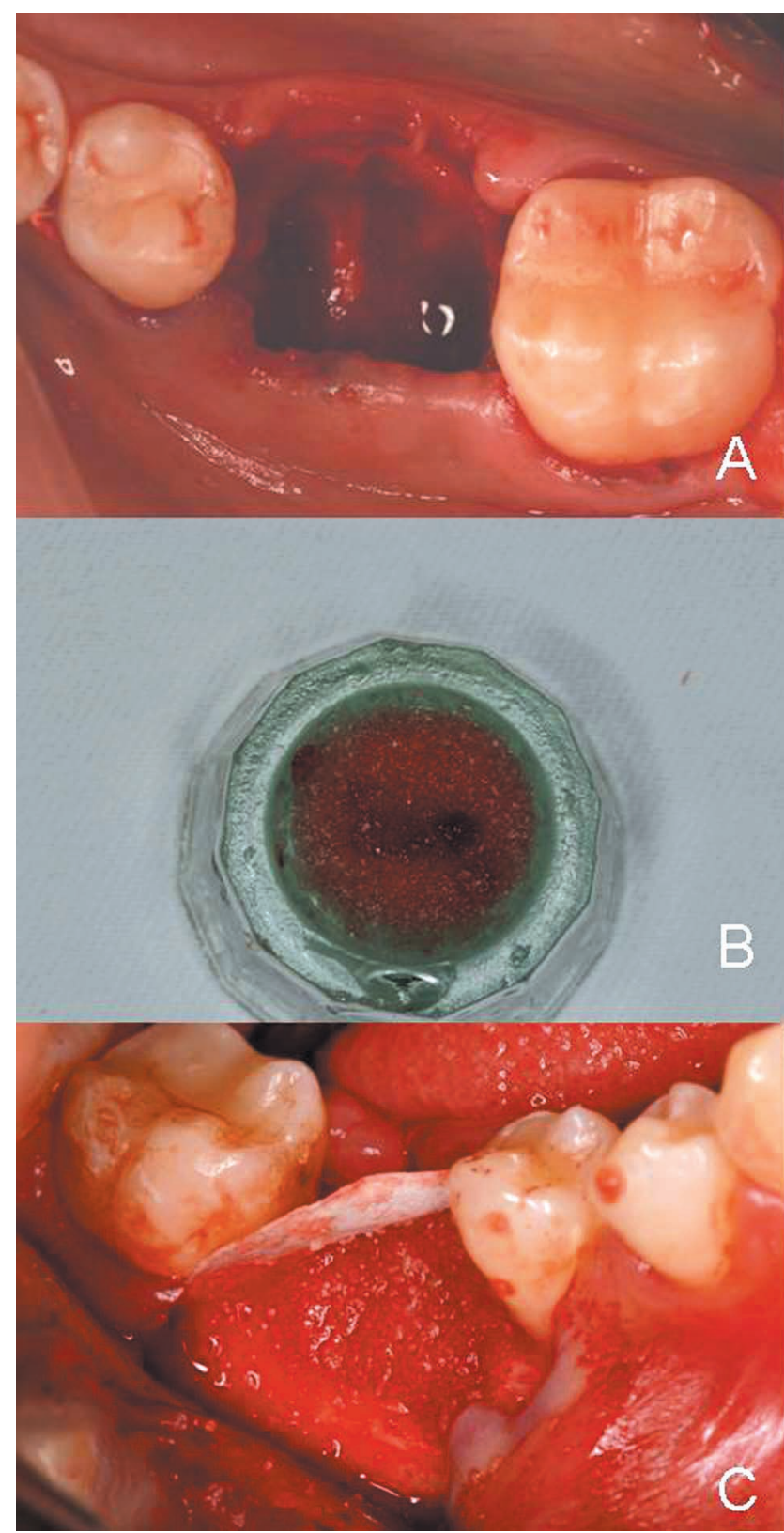

Fig. 3. Ceramic material. (A) clinical aspect of a dental socket after tooth extraction; (B) bioactive glass; (C) the biomaterial filling the socket associated with a non-absorbable barrier.

maintains the physical dimension of the augmentation during the remodeling phases (Misch \& Dietsh 1993).

2. Polymers. Polymer and composite biomaterials find application in a large number of disciplines, such as orthopedics, maxillofacial surgery, dentistry, ophthalmology, neurosurgery, gastroenterology and cardiology.

2.1.Bioerodible polimers. Polymers, such as polylactic acid (PLA), polyglycolic acid (PGA), copolymers of PLA and
PGA (PLGA), polyanhydrides, polyorthoesters, polycaprolactones, polycarbonates, and polyfumerates (Agrawal \& Ray 2001) have many properties that are wellsuited for the purposes of tissue engineering. They are nonimmunogenic, non-toxic and bioresorbable, breaking down through hydrolysis into metabolic products (although the build-up of acidic degradation products is recognised to be cytotoxic) (Sung et al., 2004). They are also convenient to process into solid-phase scaffolds for implantation or as solutions for injection and polymerisation at the site of damage. In situ polymerisable compositions, including photocrosslinkable polyanhydrides and chemical crosslinkable polyfumerates (Poshusta et al., 2003; Fisher 2002), can be easily administered in the form of arthroscopically injectable gels and liquids, and have been shown to possess adequate initial mechanical properties, controllable degradation kinetics, and the ability to simultaneously incorporate cells and growth factors to promote wound healing and support bony in-growth in vivo (Park et al., 2005; Temenoff et al., 2004). Scaffolds fabricated from unmodified synthetic polymers tend to have limited bioactivity and provide minimal biological cues to guide tissue regeneration. This can be overcome by the reintroduction of these cues in various forms - from functionalisation which alters surface charge density, to matching the underlying tissue architecture and the incorporation of peptide sequences that convey highly specific biofunctionality. For example, surface functionalisation, such as hydrolysis to expose carboxylic groups and aminolysis to expose primary and secondary amine groups, can be used to increase surface hydrophilicity, and has been found to encourage stronger interactions with serum and ECM proteins through electrostatic effects and hydrogen bonding (Croll et al., 2004). The presence of this adsorbed protein layer transforms the implant surface into a biological landscape that supports cellular interaction and is important to numerous cell-fate processes (Wilson et al., 2005).

2.2. Blood-compatible polymers.Unsaturated polyurethaneureas can be synthesized from 4,4-diphenylmethane diisocyanate, 1,2-diaminopropane, and polybutadiene containing hydroxyl groups at both ends of a chain (Ito et al. 1992). These polyurethaneureas can be cast as a film and subsequently treated with $\mathrm{N}$-chlorosulphonyl isocyanate to produce sulphamate and carboxylate groups on the film surface.

2.3. Bioactive polymers. The synthesis of a novel polyurethane block copolymer containing a covalently attached, well-oriented peptide has been reported (Lin et al. 1992). A polyurethane based on polytetramethylene oxide (PTMO) was synthesized, and a bimolecular nucleophilic substitution reaction was then employed to incorporate ethyl 
carboxylate groups onto the polymer backbone, i.e. carboxylated polyurethane. The peptide was coupled to the carboxylated polyurethane via the formation of an amide bond. This method provides a new route for grafting endlinked, bioactive peptides onto polyurethanes.

2.4 Hydrogels. Hydrogels or polyhydroxy ethyl methacrylates are three-dimensional hydrophilic polymers that swell because of their permeability to low molecular weight solutes such as a water. These materials have been extensively investigated as biomaterials, used in many cases as sustained drug-release. Drugs can be incorporated during synthesis of the polymer or added to hydrogel copolymers after they have been synthesized (Jeyanthi et al., 1991).

3. Ceramics. Ceramic materials are the most biologically acceptable of all materials. Ceramics are fully oxidized or chemically stable compounds. Because of their chemistry, ceramics are much less likely to produce any adverse effects, compared with metals and polymers, which are not as chemically stable.

Toxicological problems can result from the use of materials as substitutes for natural tissues. Concern has been expressed in the literature regarding the use of many alloys due to the production of wear particles and the release of ions by corrosion or, in the case of synthetic polymers, due to leaching of oligomer or plasticizer constituents. The argument in support of ceramics or glasses as biomaterials is that, chemically, ceramics degenerate in comparison to metals and organic-carbon-based compounds and are more were resistant. The chemical inertness of ceramics is greater than for organic or metallic materials since the overall bond strength of the three-dimensional covalent/ionic structure is greater.

The major advantage of ceramics as biomaterials is that they can be produced almost completely inert or with the potential for varying degrees of interaction within the physiological environment (Fig. 3). Thus, the surface and bulk chemistry of ceramic materials can be readily controlled. The very chemistry and structure that dictate chemical inertness of ceramic materials also dictate other unfavorable characteristics properties, such as brittleness, even though the material may have high strength, hardness, and wear resistance and a low coefficient of thermal expansion (Jones 1982).

Conclusive evidence exists to show that certain ceramic and glass compositions can bond to bone. Ceramics have a very wide application as substitutes for calcified tissues and as aid to bone formation. In the wider biomedical field, ceramic biomaterials have been used as implants for long-bone defects, as orthopedic load-bearing hip prosthesis implants, as coatings for tissue ingrowth, for spinal surgery implants, and as ceramic coatings in metal orthopedic implants (Maxian et al., 1993; Hayashi et al., 1993).

Although ceramic coatings appear to be osteoconductive, the cell and tissue mechanisms involved are not completely understood. However, the work of Davies has significantly improved the understanding of bone cell interaction with ceramic biomaterials. Burr et al. have concluded that the clinical significance of coated implants is that they allow an earlier return to normal weight bearing. The implants comprised of calcium phosphate salts and $0.5 \%$ fluoride was studied in bone defects in dog femurs. Radiological and histological examinations indicated new bone formation at the implantation sites coincident with the disappearance of the original implanted ceramic. The new kind of ceramic with fluoride in its basic composition was said to stimulate bone morphogenesis (Laufer et al., 1988).

Considerable interest has been generated about the effect of glass-ceramic implants on primary calcification. Histomorphometry and transmission electron microscopy has been used by Amir et al. (1989) to study the distribution of extracellular matrix vesicles around bone-bonding and nonbonding glass-ceramic implants in rat tibial bone. The findings support the widely acknowledged hypothesis of the role matrix vesicles in mineralization. It was shown that mineralizing tissue around bone-bonding glass-ceramics contains more matrix vesicles, which are distributed further from the front with a lower degree of calcification (Amir et al.).

Less obvious examples of the use of ceramics as biomaterials are in neurosurgical cranioplasty repair of the skull bone defects, in hand arthroplasty of the metacarpophalangeal joint, in otolaryngology as implants in the middle ear, or the use of bioglass or hydroxyapatite materials in the treatment of vocal cord paralysis. Bioactive glass containing magnetite can be used to kill bone tumors when a magnetic field is applied. Ceramics implants can also be used as drug delivery systems (Ikenaga et al., 1991).

3.1. Calcium phosphate ceramics. Calcium phosphate polycrystalline ceramic materials can be produced by precipitation from aqueous solutions and by solid-state reactions. The rationale for using hydroxyapatite as a biomaterial is the advantage of using a material having similar composition and crystalline structure as natural calcified tissues. Hydroxyapatite and other calcium-based ceramic materials can actively encourage bone regeneration at the surface of an implant. It has been postulated that the use of calcium phosphate ceramic biomaterials might replace 
the use of bone grafts in orthopedic surgery. The chemistry of these materials is now reasonably well established (Kohn \& Ducheyne, 1992) and significant animal experiments have shown these materials to be both biocompatible and bioactive.

The main purpose of using calcium phosphate ceramics as an implant material is to enable it to be gradually substituted by newly formed bone or at least to become integrated with the host bone. A major factor in the use of such materials is the control of the size of porosity. Daculsi $\&$ Passuti evaluated the effect of porosity by an in vivo experiment in the cortical bone in dogs. Three kinds of porosity were tested (from 100 to $600 \mathrm{~m} \mu$ ). The results of this study demonstrated that the porosities up to $100 \mathrm{~m} \mu$ are efficient for the bone ingrowth, however, during the first months of implantation, larger macropore sizes are more suitable for bone ingrowth.

4. Composite of Collagen and Hydroxyapatite. The natural polymer collagen that represents the matrix material of bone, teeth and connective tissue can be extracted from animal or human sources. This may involve a decalcification, purification and modification process. This discussion will focus on collagen type I because it is by far the most abundant type used in tissue engineering and its use is widely documented (Friess, 1998).

Calcium phosphates are available commercially, as hydroxyapatite extracted from bones or they can be produced wet by the direct precipitation of calcium and phosphate ions. Skeletal bones comprise mainly of collagen (predominantly type I) and carbonate substituted hydroxyapatite, both osteoconductive components. Thus, an implant manufactured from such components is likely to behave similarly, and to be of more use than a monolithic device. Indeed, both collagen type I and hydroxyapatite were found to enhance osteoblast differentiation (Xie et al., 2004), but combined together, they were shown to accelerate osteogenesis. A composite matrix when embedded with human-like osteoblast cells, showed better osteoconductive properties compared to monolithic HA and produced calcification of identical bone matrix (Serre et al., 1993; Wang et al., 1995). In addition, Col-HA composites proved to be biocompatible both in humans and in animals (Serre et al.; Scabbia \& Trombelli, 2004).

These composites also behaved mechanically in a superior way to the individual components. The ductile properties of collagen help to increase the poor fracture toughness of hydroxyapatites. The addition of a calcium/ phosphate compound to collagen sheets gave higher stability, increased the resistance to three-dimensional swelling compared to the collagen reference (Yamauchi et al., 2004) and enhanced their mechanical 'wet' properties (Lawson \& Czernuszka, 1998). This happened even when the collagen was highly crosslinked.

The direct comparison of other materials compared with Col-HA composites for bone substitutes have yet to be clearly investigated. However, increasing the biomimetic properties of an implant may reduce the problems of bacterial infections associated with inserting a foreign body (Schierholz \& Beuth, 2001). Evidence of the biological advantage compared to artificial polymeric scaffolds have been further demonstrated in cartilage regeneration (Wang et al., 2004). Polymeric scaffolds can take up to 2 years to degrade whilst Col-HA have a more reasonable degradation rate with regards to clinical use of 2 months to a year (Johnson et al., 1996). Furthermore, osteogenic cells adhered better in vitro to collagen surfaces compared to PLLA and PGA implants (El-Amin et al., 2003).

Synthetic hydroxylapatite (tricalcium phosphate [TCP]) is available in a resorbable form. As it resorbs, a readily available source of calcium becomes available in sites that have osteogenic potential. It is an osteoconductive material composed of very small, nonfused crystals, which yield cumulatively an extremely high surface area. It is a material of choice in 4 and 5 wall defects such as extraction sockets. Without grafting, such areas often will undergo facial ridge resorption, resulting in loss of the buccolingual dimension of the ridge.

5. Metals. Stainless steel and titanium or titanium alloys (i.e. Ti-6Al-4V) are the materials that usually comprise the basis of metal implants for bone regeneration. The bulk phase of the implants consists of solid metal, while titanium particle coatings create a porous surface (thickness ranging from a few nanometers to the hundreds of micrometers depending on the fabrication technique (Story et al., 1998; Harvey et al., 1999; Sul et al., 2002; Akin et al., 2001). Different techniques have been used to manufacture the porous coatings, including plasma-spraying in the case of implants with $50-60 \%$ porosity and $200-400 \mathrm{~mm}$ pore size coatings for healing femoral defects in dogs (Nishiguchi et al., 2001), or sintering in the case of implants with $35 \%$ porosity and 50-200 mm pore size coatings (Pilliar et al., 1998). Other techniques include machining, shot blasting and acid etching, but result in pore sizes of less than $10 \mathrm{~mm}$ (Pilliar $e t$ $a l$.$) . Examples of completely porous metal scaffolds are$ titanium fiber meshes with $86 \%$ porosity and a $250 \mathrm{~mm}$ average pore size that have been used for the ex vivo culture of rat bone marrow stromal cells under static conditions (van den Dokler et al., 2003) or in a low perfusion bioreactor (Sikavitsas et al., 2003) and sub sequent implantation in 
cranial defects in rats (van den Dokler et al.; Sikavitsas et $a l$.). These scaffolds have also found application as delivery systems for transforming growth factor B1 (TGF-b1) and have been used to repair rabbit cranial defects (Vehof et al., 2002). The main advantage of metal implants is their excellent mechanical properties, which makes them the most widely applied implant material used in bone surgical repairs. However, the lack of tissue adherence (Hulbert et al., 1970) and the low rate of degradation results either in a second surgery to remove the implant or in permanent implantation in the body with the related risks of toxicity due to accumulation of metal ions due to corrosion (Rubin \& Yaremchuk, 1997).

\section{CONCLUSION}

Many biomaterials are being used today, each one with its individual characteristics, but the selection of a suitable biomaterial must be determined for every case, considering the type and amount of tissue being regenerated, stability and geometric conformation of the area, vascularization of the adjacent tissues, possible inflammatory response normally associated with foreign bodies and the capacity of this material to be biodegradable and replaced by new bone tissue. Further studies may also be necessary to discovery another efficient and biocompatible materials with possible application in the bone healing process.

NASCIMENTO, C.; ISSA, J. P. M.; OLIVEIRA, R. R.; IYOMASA, M. M.; SIÉSSERE, S. \& REGALO, S. C. H. Biomateriales con aplicación en el proceso de reparación ósea. Int. J. Morphol., 25(4):839-846, 2007.

RESUMEN: Una innovación reciente en medicina es la utilización de biomateriales en la reparación de defectos óseos. Este trabajo tiene como objetivo presentar una actualización de los usos y aplicaciones de biomateriales y de sus diversos constituyentes más empleados en la reparación de los huesos.

PALABRAS CLAVE: Reparación ósea; Biomateriales; Cicatrización.

\section{REFERENCES}

Agrawal, C. M. \& Ray, R. B. Biodegradable polymeric scaffolds for musculoskeletal tissue engineering. $J$. Biomed. Mater. Res., 55(2):141-50, 2001.

Akin, F. A.; Zreiqat, H.; Jordan, S.; Wijesundara, M. B. \& Hanley, L. Preparation andanalysis of macroporous $\mathrm{TiO} 2$.lms on Ti surfaces for bone-tissue implants. $J$. Biomed. Mater. Res., 57(4):588-96, 2001.

Amir, D.; Muller, M. C.; Wendland, H.; Gross, U. \& Sela, J. Effect of glass-ceramic implants on primary calcification in rat tibial bone after injury. Biomaterials, 10(9):585-9, 1989.

Becker, W.; Becker B. E. \& Caffesse R. A comparison of demineralized freeze-dried bone and autologous bone to induce bone formation in human extraction sockets. J. Periodontol., 65(12):1128-33, 1994.

Burr, D. B.; Mori, S.; Boyd, R. D.; Sun T. C.; Blaha, J. D., Lane, L. \& Parr, J. Histomorphometric assessment of the mechanisms for rapid ingrowth of bone to HA/ TCP coated implants. J. Biomed. Mater. Res., 27(5):645-53, 1993.

Callan, D. \& Rohrer, M. D. Use of bovine-derived hydroxyapatite in the treatment of edentulous ridge defects: a human clinical and histologic case report. J.
Periodontol., 64(6):575-82, 1993.

Croll, T. I.; O’Connor, A. J.; Stevens, G.W. \& CooperWhite, J. J. Controllable surface modification of poly(lactic-co-glycolic acid) PLGA by hydrolysis or aminolysis I: physical, chemical, and theoretical aspects. Biomacromolecules, 5(2):463-73, 2004.

Daculsi, G. \& Passuti, N. Effect of the macroporosity for osseous substitution of calcium phosphate ceramics. Biomaterials, 11:86-7, 1990.

El-Amin, S. F.; Lu, H. H.; Khan, Y.; Burems, J.; Mitchell, J.; Tuan, R. S. \& Laurencin, C.T. Extracellular matrix production by human osteoblasts cultured on biodegradable polymers applicable for tissue engineering. Biomaterials, 24(7):1213-21, 2003.

Evans, G. H.; Yukna, R. A.; Cambre, K. M. \& Gardiner, D. L. Clinical regeneration with guided tissue barriers: an analysis of the current literature. Curr. Opin. Periodontol., 4:75-81,1997.

Fisher, J. P.; Vehof, J. W.; Dean, D.; van der Waerden J. P.; Holland, T. A.; Mikos, A. G. \& Jansen J. A. Soft and hard tissue response to photocrosslinked poly(propylene fumarate) scaffolds in a rabbit model. J. Biomed. Mater. Res., 59(3):547-56, 2002. 
Friess, W. Collagen - biomaterial for drug delivery. Eur. $J$. Pharm. Biopharm., 45:113-36, 1998.

Harvey, E. J.; Bobyn, J. D.; Tanzer, M.; Stackpool, G. J.; Krygier, J. J. \& Hacking, S. A. Effect of flexibility of the femoral stem on bone remodeling and fixation of the stem in a canine total hip arthroplasty model without cement. J. Bone Joint Surg. Am., 81(1):93-107,1999.

Hayashi K.; Inadome T.; Mashima T. \& Sugioka Y. Comparison of bone-implant interface shear strength of solid hydroxyapatite and hydroxyapatite-coated titanium implants. J. Biomed. Mater. Res., 27(5):557-63, 1993.

Hulbert, S. F.; Young, F. A.; Mathews, R. S.; Klawitter, J. J.; Talbert, C. D. \& Stelling, F. H. Potential of ceramic materials as permanently implantable skeletal prostheses. J. Biomed. Mater. Res., 4(3):433-56, 1970.

Ikenaga, M.; Ohura, K.; Nakamura, T.; Kotoura, Y.; Yamamuro, T.; Oka, M.; Ebisawa, Y. \& Kokubo, T. In: Bioceramics (W. Bonfield, GW Hastings, and KE Tanner, Eds.), Butterworth-Heinemen, London, 4:255-262, 1991.

Ito, Y.; Iguchi, Y. \& Imanishi, Y. Synthesis and nonthrombogenicity of heparinoid polyurethaneureas. Biomaterials., 13(3):131-5,1992.

Jeyanthi, R.; Nagarajan, B. \& Rao, K. P. Solid tumor chemotherapy using implantable collagen-poly (HEMA) hydrogel containing 5-fluorouracil. J. Pharm. Pharmacol., 43(1):60-2, 1991.

Johnson, K. D.; Frierson, K. E.; Keller, T. S.; Cook, C.; Scheinberg, R.; Zerwekh, J.; Meyers, L. \& Sciadini, M. F. Porous ceramics as bone graft substitutes in long bone defects: A biomechanical, histological, and radiographic analysis. J. Orthop. Res., 14(3):351-69,1996.

Jones, D. W. Biocompatibility of Dental Materials. In: D.C.; Smith D.C.; \& Williams D. F. Eds., CRC Press, Boca Raton, FL, 4, 1982.

Kohn, H. D. \& Ducheyne, P. Medical and Dental Materials. In: Williams D.F. Eds., VCH, Weinheim., 14:30109,1992 .

Laufer, D.; Ben-Shachar, D.; Livne, E.; Maor, G. \& Silbermann M. Enhancing effects of fluoride-containing ceramic implants on bone formation in the dogfemur. $J$. Craniomaxillofac. Surg., 16(1):40-5, 1988.

Lawson, A. C. \& Czernuszka, J. T. Collagen-calcium phosphate composites. Proc. Inst. Mech. Eng. Part. H-J Eng. Med., 212:413-25, 1998.
Lin, H. B.; Zhao, Z. C.; Garcia-Echeverria, C.; Rich, D. H. \& Cooper, S. L. Synthesis of a novel polyurethane copolymer containing covalently attached RGD peptide. $J$. Biomater. Sci. Polym., 3(3):217-27,1992.

Maxian, S. H.; Zawadsky, J. P. \& Dunn, M. G. In vitro evaluation of amorphous calcium phosphate and poorly crystallized hydroxyapatite coatings on titanium implants J. Biomed. Mater. Res., 27(1):111-7, 1993.

Misch, C. E. \& Dietsh, F. Bone grafting materials in implant dentistry. Implant. Dent., 2(3):158-67,1993.

Nishiguchi, S.; Kato, H.; Neo, M.; Oka, M.; Kim, H. M.; Kokubo, T. \& Nakamura, T. Alkali- and heat-treated porous titanium for orthopedic implants. J. Biomed. Mater. Res., 54(2):198-208, 2001.

Park, H.; Temenoff, J. S.; Holland, T. A.; Tabata, Y. \& Mikos, A. G. Delivery of TGF-betal and chondrocytes via injectable, biodegradable hydrogels for cartilage tissue engineering applications. Biomaterials, 26(34):7095-103, 2005.

Piatelli, A.; Scarano, A.; Corigliano, M. \& Piatelli, M. Comparison of bone regeneration with the use of mineralized and demineralized freeze-dried bone allografts: a histological and histochemical study in man. Biomaterials, 17(11):1127-31,1996.

Pilliar, R. M. Overview of surface variability of metallic endosseous dental implants: textured and porous surfacestructured designs. Implant Dent., 7(4):305-14, 1998.

Poshusta, A. K.; Burdick, J. A.; Mortisen, D. J.; Padera, R. F.; Ruehlman, D.; Yaszemski, M. J. \& Anseth, K.S. Histocompatibility of photocrosslinked polyanhydrides: a novel in situ forming orthopaedic biomaterial. $J$. Biomed. Mater. Res., A. 1, 64(1):62-9, 2003.

Reynolds, M. A. \& Bowers, G. M. Fate of demineralized freeze-dried bone allografts in human intrabony defects. J. Periodontol., 67(2):150-7, 1996.

Rubin, J. P. \& Yaremchuk, M. J. Complications and toxicities of implantable biomaterials used in facial reconstructive and aesthetic surgery: a comprehensive review of the literature. Plast. Reconstr. Surg., 100(5):1336-53, 1997.

Scabbia, A. \& Trombelli, L. A comparative study on the use of a HA/collagen/chondroitin sulphate biomaterial (Biostite \& Reg;) and a bovine-derived HA xenograft (Bio-Oss\&reg;) in the treatment of deep intraosseous defects. J. Clin. Periodontol., 31(5):348-55, 2004. 
Schierholz, J. M. \& Beuth, J. Implant infections: a haven for opportunistic bacteria. J. Hosp. Infect., 49(2): 87-93, 2001.

Serre, C. M.; Papillard, M.; Chavassieux, P. \& Boivin, G. In vitro induction of a calcifying matrix by biomaterials constituted of collagen and/or hydroxyapatite: an ultrastructural comparison of three types of biomaterials. Biomaterials, 14(2):97-106,1993.

Sikavitsas, V. I.; van den Dolder, J.; Bancroft, G. N.; Jansen, J. A. \& Mikos, A. G. Influence of the in vitro culture period on the in vivo performance of cell/titanium bone tissue-engineered constructs using a rat cranial critical size defect model. $J$. Biomed. Mater. Res A., 67(3):944-51,2003.

Smukler, H.; Landi, L. \& Setayesh, R. Histomorphometric evaluation of extraction sockets and deficient alveolar ridges treated with allograft and barrier membrane: a pilot study. Int. J. Oral. Maxillofac. Implants., 14(3):407-16, 1999.

Story, B. J.; Wagner, W. R.; Gaisser, D. M.; Cook, S. D. \& RustDawicki, A. M. In vivo performance of a modified CSTi dental implant coating. Int. J. Oral Maxillofac. Implants., 13(6):749-57,1998.

Sul, Y. T.; Johansson, C. B.; Jeong, Y.; Wennerberg A. \& Albrektsson T. Resonance frequency and removal torque analysis of implants with turned and anodized surface oxides. Clin. Oral Implants. Res., 13(3):252-9,2002.

Sul, Y. T.; Johansson, C. B.; Petronis, S.; Krozer, A.; Jeong, Y.; Wennerberg, A. \& Albrektson, T. Characteristics of the surface oxides on turned and electrochemically oxidized pure titanium implants up to dielectric breakdown: the oxide thickness, micropore con.gurations, surface roughness, crystal structure and chemical composition. Biomaterials, 23(2):491-501,2002.

Sul, Y. T.; Johansson, C.B.; Roser, K. \& Albrektsson, T. Qualitative and quantitative observations of bone tissue reactions to anodized implants. Biomaterials, 23(8):1809-17, 2002.

Sung, H. J.; Meredith, C.; Johnson, C. \& Galis, Z.S. The effect of scaffold degradation rate on three-dimensional cell growth and angiogenesis. Biomaterials. 25(26):5735-42,2004.

Temenoff, J. S.; Park, H.; Jabbari, E.; Sheffield, T. L.; LeBaron, R. G.; Ambrose, C. G. \& Mikos, A.G. In vitro osteogenic differentiation of marrow stromal cells encapsulated in biodegradable hydrogels. J. Biomed. Mater. Res A., 70(2):23544,2004 .

van den Dokler, J.; Farber, E.; Spauwen, P. H. \& Jansen, J. A. Bone tissue reconstruction using titanium fiber mesh combined with rat bone marrow stromal cells. Biomaterials, 24(10): 1745-50,2003.
Vehof, J. W.; Haus, M.T.; de Ruijter, A. E.; Spauwen, P. H.; \& Jansen, J.A. Bone formation in transforming growth factor beta-I-loaded titanium ber mesh implants. Clin. Oral Implants Res., 13(1):94-102,2002.

Xie, J.; Baumann, M. J.; \& McCabe, L. R. Osteoblasts respond to hydroxyapatite surfaces with immediate changes in gene expression. J. Biomed. Mater. Res A., 71(1):108-17, 2004.

Yamauchi, K.; Goda, T.; Takeuchi, N.; Einaga, H. \& Tanabe, T. Preparation of collagen/calcium phosphate multilayer sheet using enzymatic mineralization. Biomaterials, 25(24): 54819, 2004.

Yukna, R. A. Clinical evaluation of coralline calcium carbonate as a bone replacement graft material in human periodontal osseous defects. J. Periodontol., 65(2):177-85, 1994.

Yukna, R. A.; Callan, D. P.; Krauser, J.T.; Evans, G. H.; Aichelmann-Reidy, M. E.; Moore, K.; Cruz, R. \& Scott, J. B. Multi-center clinical evaluation of combination anorganic bovine-derived hydroxyapatite matrix $(\mathrm{ABM}) /$ cell binding peptide (P-15) as a bone replacement graft material in human periodontal osseous defects: 6-month results. J. Periodontol., 69(6):655-63, 1998.

Wang, R. Z.; Cui, F. Z.; Lu, H. B.; Wen, H. B.; Ma, C. L. \& Li, H. D. Synthesis of Nanophase Hydroxyapatite Collagen Composite. J. Mater. Sci. Lett., 14:490-2,1995.

Wang X.; Grogan S.P.; Rieser F.; Winkelmann V.; Maquet V.; Berge M.L.; \& Mainil-Varlet P. Tissue engineering of biphasic cartilage constructs using various biodegradable scaffolds: an in vitro study. Biomaterials, 25(17):3681-8, 2004.

Wilson, C. J.; Clegg, R. E.; Leavesley, D. I. \& Pearcy, M. J. Mediation of biomaterial-cell interactions by adsorbed proteins: a review. Tissue Eng., 11(1-2):1-18, 2005.

Zaner, D. J. \& Yukna, R. A. Particle size of periodontal bone grafting materials. J. Periodontol., 55(7):406-9,1984.

Correspondence to:

Dr. Cássio do Nascimento

Faculdade de Odontologia de Ribeirão Preto - USP

Departamento de Materiais Dentários e Prótese

Av. Café $\mathrm{S} / \mathrm{N}$,

CEP: 14040-904

Ribeirão Preto, SP

BRAZIL

Phone: +55-16-36024095

Fax: +55-16-36330999

E-mail:cassionasc@forp.usp.br

Received: 24-05-2007

Accepted: 29-08-2007 